\title{
Nano ES GEMMA and PDMA, New Tools for the Analysis of Nanobioparticles-Protein Complexes, Lipoparticles, and Viruses
}

\author{
Günter Allmaier, ${ }^{a}$ Christian Laschober, ${ }^{\mathrm{a}, \mathrm{b}}$ and \\ Wladyslaw W. Szymanski ${ }^{\mathrm{b}}$ \\ a Institute of Chemical Technologies and Analytics, Vienna University of Technology, Vienna, Austria \\ ${ }^{\mathrm{b}}$ Faculty of Physics, University of Vienna, Vienna, Austria
}

Differential mobility analysis (DMA) is a technique suited for size analysis as well as preparative collection of airborne nanosized airborne particles. In the recent decade, the analysis of intact viruses, proteins, DNA fragments, polymers, and inorganic nanoparticles was possible when combining this method with a nano-electrospray charge-reduction source for producing aerosols from a sample solution/suspensions. Mass analysis of high molecular weight noncovalent complexes is also possible with this methodology due to the linear correlation of the electrophoretic mobility diameter and the molecular mass. In this work, we present the analysis (size and molecular mass) of high molecular weight multimers (noncovalent functional homocomplex) of Jack bean urease in a mass range from $275 \mathrm{kDa}$ up to 2.5 $\mathrm{MDa}$, with mainly present tri- and hexamers but also higher oligomers of the $91 \mathrm{kDa}$ monomer subunit. In a second experiment, the size analysis of intact very-low-density $(\sim 35 \mathrm{~nm})$, low-density $(\sim 22 \mathrm{~nm})$ and high-density lipoparticles $(\sim 10 \mathrm{~nm})$, which are heterocomplexes consisting of cholesterol, lipids, and proteins in different ratios, is presented. Results from mobility analysis were in excellent agreement with particle diameters found in literature. The last presented experiment demonstrates size analysis of a rod-like virus and selective sampling of a selected size fraction of electrosprayed, singly-charged tobacco mosaic virus particles. Sampling and subsequent transmission electron microscopic investigations of a specific size fraction (40 nm electrophoretic mobility diameter) revealed the folding of virus particles during the electrospray and charge reduction (electrical stress) as well as solvent evaporation (mechanical stress) process, leading to an observed geometry of 150 (length) $\times 35$ (width) nm (average cylindrical geometry of unsprayed intact virus $300 \times 18 \mathrm{~nm}$ ). (J Am Soc Mass Spectrom 2008, 19, 1062-1068) @ 2008 American Society for Mass Spectrometry

$\mathrm{N}$ oncovalent interactions of proteins are of great interest as they play a vital part in biology and medicine such as blood coagulation, gene expression [1, 2], immune recognition [3], and formation of lipoparticles [4] and viruses. Analysis of the formation process, stoichiometry, and molecular weight of those complexes can be very challenging as noncovalent interactions can easily be destroyed or biased when leaving specific native conditions [5], and as their molecular mass can easily exceed the working range of modern mass spectrometry. For these reasons, a demand for new analytical techniques, which preserve noncovalent interactions, deliver molecular mass and/or size related information (in contrast to capillary electrophoresis and native gel electrophoresis) and which have a working range that exceed conventional mass spectrometry, exists.

Address reprint requests to Professor G. Allmaier, Institute of Chemical Technologies and Analytics, Vienna University of Technology, Getreidemarkt 9/164-IAC, A-1060 Vienna, Austria. E-mail: guenter.allmaier@tuwien.ac.at
Differential mobility analysis (DMA) is a technique developed to classify charged aerosolized particles under ambient pressure according to their electrophoretic mobility diameter [6]. In the recent decade, its working range was extended from $\mu \mathrm{m}$ down to the $\mathrm{nm}$ size range [7], or in terms of molecular mass, into the $\mathrm{kDa}$ to GDa molecular mass range, thus closing the gap between classic aerosol particle technology (low $\mu \mathrm{m}$ into $\mathrm{mm}$ range) and mass spectrometry (sub- $\mathrm{nm}$ to $10 \mathrm{~nm}$ ). The size range of 10 to $200 \mathrm{~nm}$ is therefore of great interest, and covered by the so-called nano-differential mobility analysis (nano DMA) [8]. Combined with a modified nano electrospray source (nES) for nanoaerosol generation, and bipolar charging process to deliver mostly singly charged ions $[9,10]$, it has been demonstrated that the analysis of intact biospecific protein complexes [11, 12], viruses [11], virus antibody [13], virus receptor [13], bacterio phages [14], and polymers $[15,16]$ is possible, and delivers a lot of new knowledge.

In this work, we present new interesting applications 
of nES DMA technology with two types of instruments, namely nES gas-phase electrophoretic mobility molecular analyzer (GEMMA) and parallel DMA (PDMA). Briefly, the GEMMA system $[8,11]$ is based on the electrospraying of the sample solution by means of voltage and supported by sheath gas flow of particlefree air and $\mathrm{CO}_{2}$ followed by charge reduction via a bipolar atmosphere (generated by a polonium-210 source) of the multiple charged aerosol particles to singly positive or negative charged particles/ions (approximately $1 \%$ of all aerosolized particles) and a huge number of neutral particles (approximately 99\%). These ions are transferred to the nano DMA (a particular form of an ion mobility spectrometer operated at atmospheric pressure) where the charged nanobioparticles are separated according to their electrophoretic mobility in a laminar flow of particle free air (several L/min of air flow) with an orthogonal voltage scan. The sizeseparated charged particles are transferred to the detector, which in the case of GEMMA is a condensation particle counter based on direct optical detection of particles. The PDMA consists of the same components except that the detector is a Faraday cup detector (due to faster response time compared with condensation particle counter detectors), and a collector unit is attached (see Figure 1a). The source of singly charged particles and the way they are generated are identical to the GEMMA system. Afterwards the airborne charged particles are either for a short time completely transferred into the scanning nano DMA and a complete size spectrum is obtained with the Faraday cup detector (Figure 1b.) Afterwards the operator selects a peak or size of interest and the correlating scan voltage is automatically transferred to the sampling nano DMA with attached electrostatic particle sampler (Figure 1a and c). By applying a certain voltage in the sampler, the size-separated charged particles are deflected to the TEM grid (Figure 1c).

First, we show the GEMMA analysis of the high mass functional biocomplex of urease (isolated from jack bean), which is known to form multimers up to 3 MDa molecular mass [17, 18]. The biologically relevant complex is a hexameric particle consisting of six identical proteins (molecular weight $90.77 \mathrm{kDa}$, Swiss-Prot entry P07374) resulting in a particle with a molecular mass of $544.62 \mathrm{kDa}$, which is an example of a metalloenzyme containing 12 nickel atoms. The second example shows the particle size analysis of intact high density (HDL), low density (LDL), and very low density (VLDL) lipoprotein particles [4] isolated from human plasma and ranging in size from 7 to $120 \mathrm{~nm}$. This functional biocomplex is of particular interest because it consists not only of different proteins (heterocomplex) but contains also a huge amount of lipid molecules, namely triglycerides, cholesterol and its ester, and phospholipids. The analysis of blood concentration as

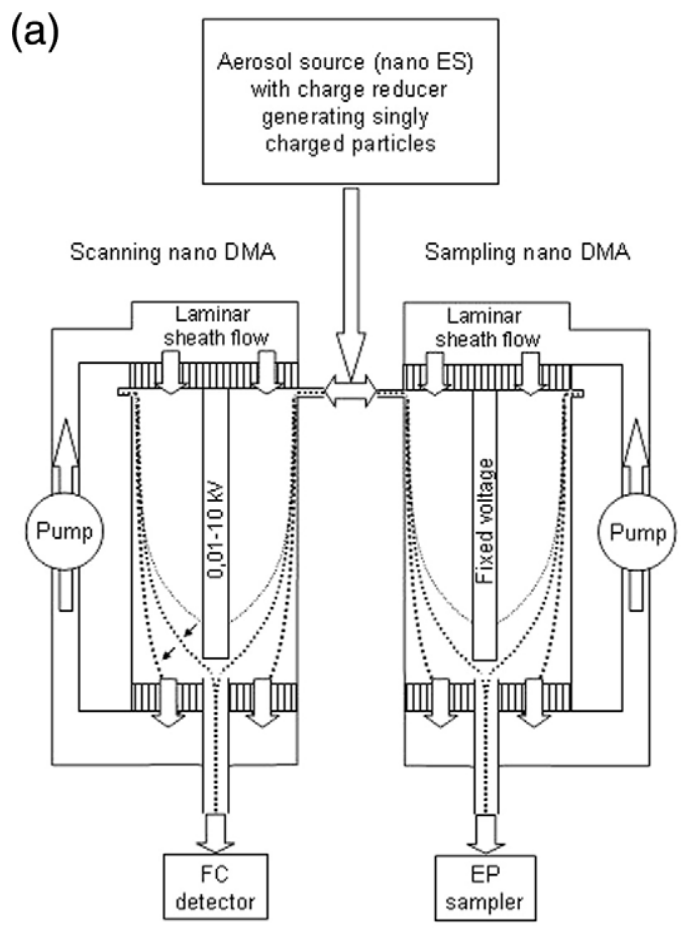

(b)

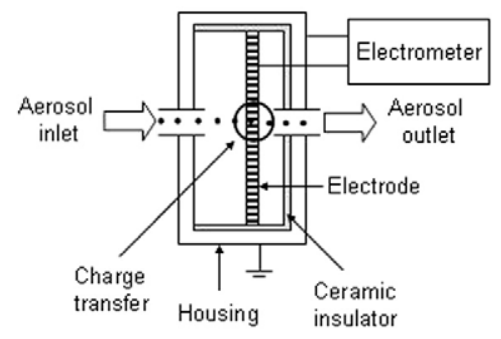

(c)

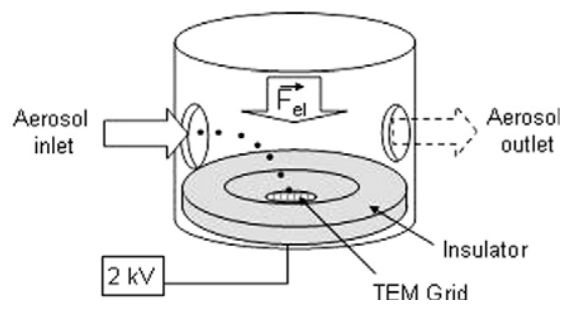

Figure 1. Schematic of the nano ES (aerosol source) PDMA (parallel differential mobility analyzer) system (a) used, consisting of a scanning nano DMA (analytical DMA with FC detector) and a sampling nano DMA (collector DMA with EP sampler), a Faraday cup (FC) detector (b), and an electrostatic particle (EP) sampler (c). 
well as size distribution [19-22] of these lipoparticles is of great diagnostically importance for assigning the risk of cardiovascular and other lipid-connected health risks [23]. A recently granted U.S. patent indicates the use of GEMMA for a medical application in this field [24], and a brief mention was also given in a recent review article by Kaddis and Loo [8]. Furthermore, many subfractions of these particles (e.g., IDL or chylomicrons) were identified by analytical techniques such as NMR spectroscopy, gel electrophoresis, and vertical auto-profiling (ultracentrifugation), which allow the quantification of the various lipoparticles as a function of their size [23]. In the last application, the analysis and sampling of cylindrical (approximately 300 (length) $\times 18-20 \mathrm{~nm}$ (o.d.) with an inner channel of approximately $4 \mathrm{~nm}$ ) tobacco mosaic virus (TMV) particles [25] —an RNA virus that infects plants, especially members of the family Solanaceae, and is composed of proteins, viral RNA and other small molecules-by means of a parallel DMA (which is an extension of the GEMMA system applied for the previous two applications) is presented.

\section{Experimental}

\section{Materials}

HDL, LDL, and Jack bean (Canavalia ensiformis) urease were purchased from Sigma-Aldrich (L8039, L7914, U1500; St. Louis, MO). HDL ( $\alpha$-lipoprotein) and LDL ( $\beta$-lipoprotein) were isolated from human plasma by ultracentrifugation and obtained in $150 \mathrm{mM}$ sodium chloride with $0.01 \%$ EDTA (pH 7.4) solution. VLDL (pre- $\beta$-lipoprotein) was provided by the working group of D. Blaas (Medical University of Vienna) after ultracentrifugation. TMV samples were provided by the group of F. L. Dickert (University of Vienna). All samples were purified to remove or reduce involatile additives via dialysis against a $20 \mathrm{mM}$ ammonium acetate buffer solution ( $\mathrm{pH}$ 6.5), which was prepared from distilled water and analytical grade ammonium acetate for mass spectrometry (73,594; Sigma-Aldrich, St. Louis, MO). All samples (urease and lipoparticles) were diluted to a final concentration of about $50 \mu \mathrm{g} / \mathrm{mL}$ by means of the mentioned ammonium acetate solution to avoid unspecific dimer and oligomer formation [7]. TMV samples, ready for spraying, had a concentration of approximately $100 \mu \mathrm{g} / \mathrm{mL}$. In case of the urease, even lower concentrations were used to verify the specificity of hexameric complex formation. The internal calibrant for the urease experiments was an immunoglobulin G (Octapharma, Vienna, Austria) analyzed by SDS-PAGE, capillary gel electrophoresison-the-chip and MALDI mass spectrometry (in terms of homogeneity and molecular mass).

\section{n-ES Conditions for GEMMA and PDMA}

The nano-electrospray (n-ES) source (aerosol source, model 3480; TSI Inc, Shoreville, MN) was operated with
$1.8 \mathrm{kV}$ positive polarity. The sample liquid was forced through the capillary $(40 \mu \mathrm{m}$ i.d.) with a pressure difference of 4 psi resulting in a flow of $\sim 70 \mathrm{~nL} / \mathrm{min}$ sample flow. A sheath flow of $1 \mathrm{~L} / \mathrm{min}$ compressed air and $0.4 \mathrm{~L} / \mathrm{min} \mathrm{CO}_{2}$ (Air Liquide, $99.995 \%$ ) was set to prevent corona discharge at the tip of the spray needle and to achieve a stable spray in the necessary cone jet mode [26]. $\mathrm{A} \mathrm{Po}^{210} \alpha$ radiation source $(5 \mathrm{mCi}$, model P-2042 Nucleospot local air ionizer; NRD, Grand Island, $\mathrm{NY}$ ) is embedded in the nano ES source and leads to a bipolar charging atmosphere. The highly charged nanodroplets, generated via electrospray process in the cone-jet mode, were transformed in the bipolar atmosphere into neutral and singly positively and negatively charged particles $[9,10]$. The so generated particles are transferred into the separation device (nano DMA in case of GEMMA or scanning nano DMA/sampling nano DMA in case of PDMA system).

\section{GEMMA and PDMA}

GEMMA. The differential mobility analyzer [7] (model 3980; TSI Inc for a more detailed description see www.tsiinc.de/documents/3980C.pdf) was operated in a sizing range between 3 and $67 \mathrm{~nm}$ with $15 \mathrm{~L} / \mathrm{min}$ sheath air to achieve maximum resolution of 20 . The central electrode was operated with negative polarity, thus analyzing the singly positively charged particle fraction. The classified [separated according to their electrophoretic mobility (EM) diameter)] particles were detected with a condensation particle counter (model 3025; TSI Inc.) suited for single particle detection, resulting in a limit of detection of about $10^{3}$ particles $/ \mathrm{cm}^{3}$ aerosol.

PDMA. For the experiments with the TMV tobacco mosaic virus, a parallel DMA (PDMA) [27] system (Figure 1a) was used and the setup consisting of two identical in-house built nano DMAs, one connected with an in-house built classic Faraday cup (FC) detector [28] (Figure 1b) and the other with a self-assembled electrostatic particle (EP) sampler (Figure 1c). Both nano DMAs, one, the scanning (scan voltage from $10 \mathrm{~V}$ to 10 $\mathrm{kV}$ ) nano DMA, for obtaining a complete size spectrum, and the other, the sample nano DMA on a specific central voltage, for selecting a particular size range (in this case $40 \mathrm{~nm}$ ), which is of interest and leads subsequently to the sampling/collecting of a specific particle size fraction. Both nano DMAs were operated with 20 $\mathrm{L} / \mathrm{min}$ sheath gas flow and a starting size of $10 \mathrm{~nm}$.

\section{Sampling Device of PDMA}

The in-house built EP sampler [29] (Figure 1c) suited for sampling nanometer sized particles was operated with $2 \mathrm{kV}$ deflection voltage applied to a transmission electron microscopy (TEM) grid (BalTec S160, $3 \mathrm{~mm}$ diameter, $20 \mathrm{~nm}$ carbon film). The ES sampler was positioned in sequence closely to the exit of the sampling nano 
DMA of the PDMA system, allowing the sampling of the classified size fraction. For TMV sample, a collection time of $2 \mathrm{~h}$ was applied. Afterwards, the TEM grid with the collected TMV was removed from the EP sampler and TEM images were obtained by means of a Philips CM12 electron microscope. With the same microscope and under identical conditions, the TMV solution before introduction into the PDMA system was analyzed.

\section{Results and Discussion}

\section{High Molecular Mass Noncovalent Protein Complex}

The GEMMA spectrum of jack bean urease (Figure 2) shows various clearly distinguishable peaks. The first peak at $9.6 \mathrm{~nm}$ corresponds to an internal calibrant (immunoglobulin G). This size corresponds to $148 \mathrm{kDa}$ molecular mass when applied to an external protein-based calibration [11], which is practically identical to the theoretical value within the confidence interval of the calibration curve $\left(R^{2}=0.996\right)$. We want to mention that the calculation of the molecular mass for proteins and complexes below two million $\mathrm{Da}$ is based on the following validated correlation: $\mathrm{M}(\mathrm{EMD}, \rho)=\left(\pi \times \mathrm{EMD}^{3} / 6\right) \times$ $\rho \times \mathrm{N}_{\mathrm{A}}, \mathrm{M}$, molecular mass; EMD, electrophoretic mobility diameter; $\rho$, density of particle/ion; $\mathrm{N}_{\mathrm{A}}$, Avogardo's number $[8,11]$. Thus, no further correction of the molecular mass analysis of the noncovalent complexes of urease was necessary. At $11.7 \mathrm{~nm}$, the first peak attributable to urease appears. This diameter value corresponds to a molecular mass of $275 \mathrm{kDa}\left([3 \mathrm{M}]^{+}\right)$, or to a trimer of the $91 \mathrm{kDa}$ [17] monomer of urease (also known as the so-called A1 unit). The most abundant peak in the GEMMA spectrum at $14.7 \mathrm{~nm}\left([6 \mathrm{M}]^{+}\right)$ corresponds to an intact hexameric urease (spherical so-called $\alpha$-unit at $560 \mathrm{kDa}$ compared with the theoretical value of $546 \mathrm{kDa}$. This result matches well with

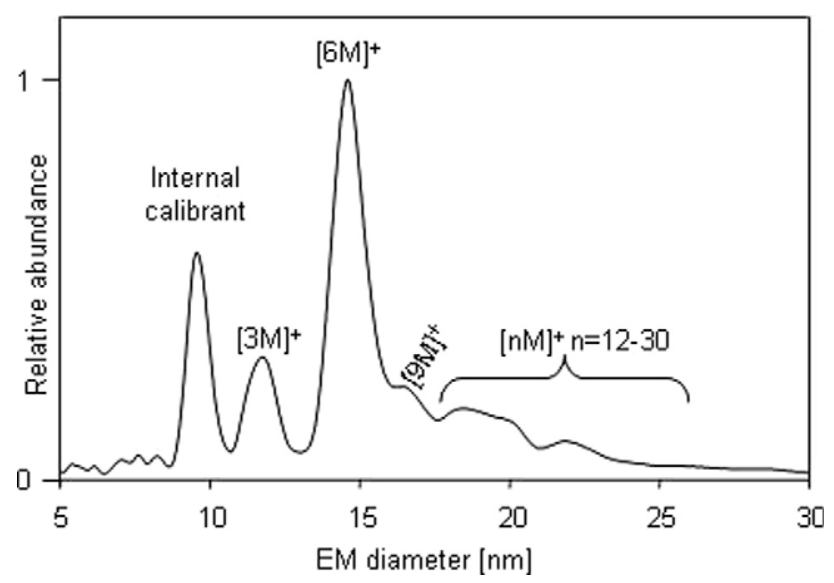

Figure 2. GEMMA spectrum of the noncovalent homocomplex of Jackbean urease $(50 \mu \mathrm{g}$ urease $/ \mathrm{mL})$. Besides the dominating hexameric $\left([6 \mathrm{M}]^{+}\right)$complex, a nonamer $\left([9 \mathrm{M}]^{+}\right)$, as well as unresolved oligomers are present and a trimer corresponding to $[3 \mathrm{M}]^{+}$ or $[6 \mathrm{M}]^{2+}$. An internal calibrant (immunoglobulin G) was added to the urease solution.

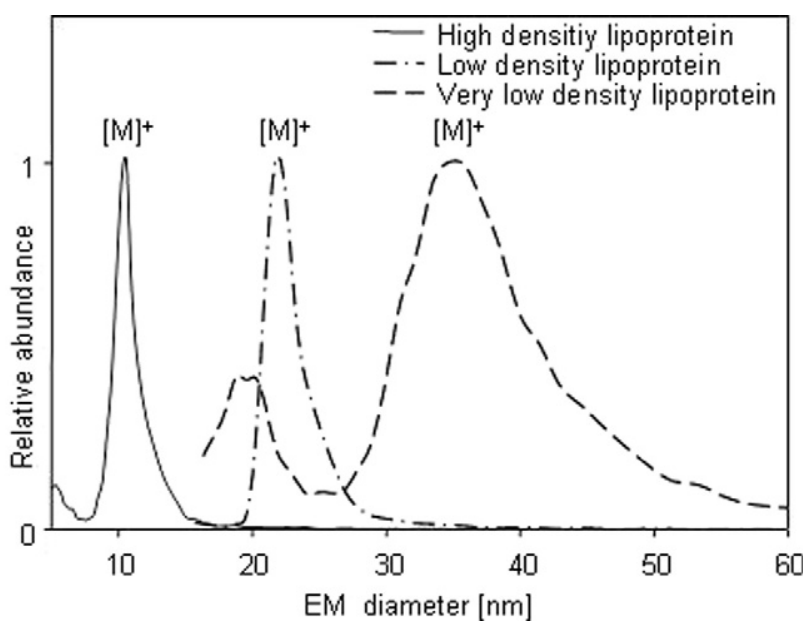

Figure 3. Overlaid GEMMA spectra of three different types of human lipoprotein particles at a concentration of $50 \mu \mathrm{g}$ lipoparticles/mL (high density lipoprotein, low density lipoprotein, and very low density lipoprotein nanoparticle).

literature, where experiments have shown that urease forms tri- and hexamers, under certain conditions with the hexamer as the dominant biological active form under physiological conditions and the trimer as a intermediate before complete dissociation, for example at high or low $\mathrm{pH}$ [18]. Low abundant but not wellresolved peaks appear at $16.8 \mathrm{~nm}$ and between 18 and $22.5 \mathrm{~nm}$, corresponding to $[9 \mathrm{M}]^{+}$and $[12-30 \mathrm{M}]^{+}$aggregates, indicating that urease might have a tendency to form less abundant high molecular weight complexes formed from the more stable trimeric and hexameric particles. How far these high molecular mass aggregates are of biological importance cannot be said at this point but might be of value for future investigations of functional protein complexes. The GEMMA tool might give indications for complexes, which could not be detected by other techniques as size exclusion chromatography or analytical ultracentrifugation due to the low sensitivity of these techniques.

\section{Lipoprotein Particles}

In Figure 3 the GEMMA size spectra of VLDL, LDL, and HDL are shown. VLDL is composed of $50 \%$ triacylglycerols, $20 \%$ phospholipids, $10 \%$ cholesterinesters, and $10 \%$ proteins [4]. The function of VLDL is the transport of lipids from liver to peripheral organs directly after the digestion process and is converted afterwards to LDL. As can be seen, the size spectrum of VLDL shows a broad size distribution between 27 and $50 \mathrm{~nm}$, with a maximum at about $35 \mathrm{~nm}$, which agrees well with values found in literature $[4,30]$. The broad distribution correlates to the task of transporting endogenous lipids. LDL particles contain $10 \%$ triacylglycerines, $20 \%$ proteins, $20 \%$ phospholipids, and $40 \%$ cholesterinesters, and functions as a fast accessible cholesterin reservoir. From medical studies, it is known that its average size and blood level are possible predictors for cardiovascu- 
lar disease [23] (better than the cholesterol concentration contained within the LDL particles) and that the abundance of a small, dense subfraction are an indicator for arthrogenic dyslipidemia [31]. The GEMMA analysis shows, compared with VLDL, a narrow size distribution with an average size of $21.7 \mathrm{~nm}$, which also corresponds well with data $(22 \mathrm{~nm})$ from literature [4, 23]. HDL is the densest lipoparticle due to the highest percentage of proteins and smallest in size containing $50 \%$ proteins, $25 \%$ phospholipids, and $15 \%$ cholesterinesters. Its function is to collect excess cholesterol from the periphery and to deliver it at the liver or release it for the production of steroid hormones [4]. Its particle size varies between 8 and $11 \mathrm{~nm}$, with a correlation between cholesterol levels and HDL size [32]. The GEMMA size spectrum shows a sharp peak at $10 \mathrm{~nm}$, which is also in agreement with literature data [4, 32]. In the medical field, exact and fast size determination of lipoparticles and their subspecies might be used for deeper understanding of lipid biochemistry in humans and health risk assessment [8c, 24] instead of indirect techniques as the Friedewald method [33] or other in the introduction mentioned sophisticated and timeconsuming methods. This example might be helpful and inspiring to investigate various kinds of sophisticated drug delivery systems, e.g., liposomes, dendrimers [15], or cell compartments.

\section{Collection of Intact Tobacco Mosaic Virus}

Before we start a brief description of the operation of the PDMA system, we give the major reasons for the construction and use of this device. First, due to the facts that the system is operated at atmospheric pressure and in a continuous mode (electrospraying and charge reduction was tested successfully up to $24 \mathrm{~h}$ ), a collection of separated singly charged bioparticles (ions) seems to be of general interest for subsequent analysis (e.g., TEM of the size-selected particles). A critical factor for optimal and reproducible separation of particles/ions by means of a nano DMA in general is the laminar air flow, particularly if done over long time periods [6-8]. Therefore, an analytical (scanning) nano DMA and a collector (sampling) nano DMA were run in parallel (Figure 1a), splitting the stream of singly charged bioparticles (coming from the nano ES) before entering the nano DMAs to guarantee identical flow conditions in the scanning (analytical) nano DMA and sampling (collector) nano DMA. The analytical nano DMA with the Faraday cup detector (Figure 1b) is continuously scanning the whole size range (indicating any changes in the size spectrum of the electrosprayed sample) and the determined maximum in size (at a particular DMA voltage) is transferred after selection by operator automatically to the sampling nano DMA. Then, the whole stream of singly charged particles flows into the sampling nano DMA (and at certain time points the stream of particles is switched back to the scanning nano DMA for checking the full size spectrum of the sample). So the collector nano DMA allows only the passage of charged particles with the selected particular size, which, after leaving the central electrode of the DMA, are collected by the EP sampler (Figure 1c). A perpendicular (to the flow direction of the aerosol flow) electrical field directs the separated charged particles onto the TEM grid. Afterwards, the grid with the attached size-selected particles can be removed for further investigations. This experimental procedure is illustrated with a solution of a rod-shaped virus (TMV). In Figure 4a, the TEM image (staining with uranylium acetate) of a diluted aqueous ammonium acetate-containing TMV solution exhibits a sharp, black colored shell of the virus. As was derived from the picture, the virus particles possess a uniform thickness of $18 \mathrm{~nm}$ o.d., which corresponds with the known viral structure [34]. The length of the observed viral particles varies significantly (from a length from 120 up to $1000 \mathrm{~nm}$ ). It is known that the intact virus particle possesses an average length of about $300 \mathrm{~nm}$ and the shorter TMV particles are probably either unfinished or, through the isolation process from cell culture, destroyed. Longer TMV particles seem to be more than one TMV particle (a)

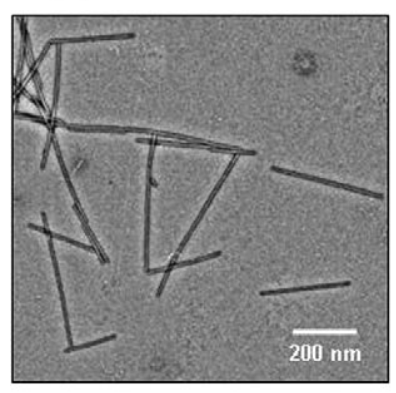

(b)

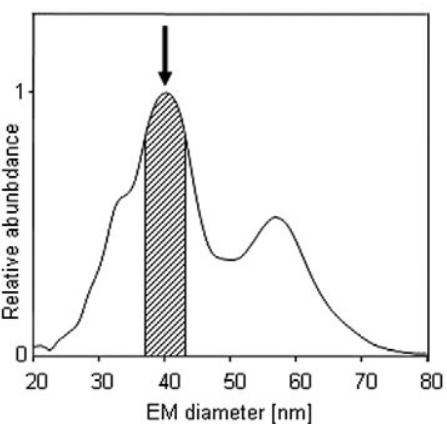

(c)

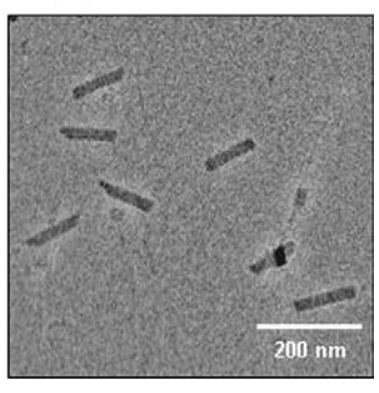

Figure 4. The TEM image of diluted TMV solution (100 $\mu \mathrm{g} / \mathrm{mL})$ before analysis (a). PDMA spectrum from scanning/analytical nano DMA with FC detector of TMV. The PDMA sampling (collector) nano DMA was operated at the EM diameter maximum of the hatched area (b). The TEM image of the TMV collected by the EP sampler after collector nano DMA passage (c). 
with a head-on position attached, which can be seen at sharp bends that appear along the length of these particles. Size analysis of the TMV virus by means of the PDMA (Figure 4b) shows two relatively broad peaks (bimodal distribution), with a maximum at 40 (arrow in Figure $4 \mathrm{~b}$ ) and $60 \mathrm{~nm}$. Based on the length distribution of the stock solution that was electrosprayed, it can be assumed that the peak at 40 and $60 \mathrm{~nm}$ cannot be easily correlated with sizes of the TEM analysis done on the starting solution. The bimodal size distribution at $40 \mathrm{~nm}$ might represent single and at $60 \mathrm{~nm}$ particles consisting of two or more attached viruses (which can be seen TEM image of starting solution Figure 4a). To investigate this working hypothesis, the size fraction at $40 \pm 2$ nm was selected (by means of collector nano DMA) with the PDMA for deposition on an electron microscopic grid. TEM analysis of the sampled size fraction (Figure 4c) shows relatively uniform structures with much less contrast than the intact TMV particles, leading to the assumption that the protein shell was injured and the uranylium acetate as staining substance was able to enter the viral shell leading to a more uniform staining of the viral particles. Size analysis (via the TEM image) of the deposited particles leads to dimensions of $150 \pm 12 \mathrm{~nm}$ (length) $\times 35 \pm 4 \mathrm{~nm}$ (width of the nanobioparticle in the plain of the TEM grid), with most particles showing a small edge at the half of the shorter side. After a closer look at the dimensions, it is apparent that the length is half of the length and the diameter double the diameter of an intact single TMV particle. This observation and the small edge in the middle of the width lead to the conclusion that the sampled virus particles are indeed single TMV particles, which were folded in the middle, probably during the electrospray and water evaporation step, which may lead, as the droplets containing the TMV particles are getting smaller, to a bending of the rod-like particles, until the forces are high enough to break or bend them in the middle. A similar behavior was also described by Hogan et al. [14b] for the bacteriophages T2 and T4, but with the consequence that these nanobioparticles were broken apart. This experiment demonstrates that singly charged bioparticles as viruses can be size-separated and collected by means of the PDMA system and used for further investigations. This proof-of-principle experiment corroborates the experiments of Siuzdak et al., demonstrating the viability of TMV and rice yellow mottle virus after ESI and passage of a quadrupole analyzer (vacuum system) with subsequent soft collection by means of a gelatinous layer [35]. It will open up new avenues of research (in terms micropreparative collection) in a number of fields, where the integrity and viability of nanobioparticles are of importance (e.g., drug carrier or vaccine particles). The use of such a device in the emerging field of nanotechnology, e.g., high-resolution size-fractionation (and simultaneous analysis) of carbon nanotubes, quantum dots, or titanium dioxide particles may open up new possibilities when considering mas- sive parallel nano electrospraying with efficient charge reduction [36].

\section{Conclusions}

The presented applications show that differential ion mobility/GEMMA analysis is indeed suited to analyze high molecular weight noncovalent complexes and complex distributions, which are in a molecular mass regime not accessible to mass spectrometry with high accuracy. Furthermore, this technique is able to determine the size and size distribution of intact lipoprotein particles and subspecies, which are nanobioparticles of quite heterogenous composition, in a more convenient way than in actual medical diagnosis, where their size is mainly determined routinely by the mentioned Friedewald method [33]. Additionally it has been demonstrated that it is possible to analyze nanobioparticles as tobacco mosaic virus particles, and to collect a specific size fraction out of the rather polydisperse sample containing finished, unfinished, or degraded and attached virus species with the PDMA system. The TEM analysis of the sampled size fraction showed great uniformity of the collected viral particles and could actually - a rather unexpected result-reveal that the tobacco mosaic virus was folded during the electrospray and droplet drying process. This result is caused by, to a certain extent in a mechanical way [14b], TMV folding into half and not simply letting both ends protrude from the droplet surface during droplet evaporation (TMV length of $300 \mathrm{~nm}$ and a diameter of $18 \mathrm{~nm}$ compared with $160 \mathrm{~nm}$ average droplet diameter at the beginning). The experiments clearly show that singly charged nanobioparticles (e.g., rod-like and spherical viruses, lipoparticles, or functional protein complexes) can be collected by means of the PDMA system and used for further analysis. The development of multinano ES capillary sources with a replacement of the radioactive source by a corona discharger [36] and nano DMAs with improved resolving power [37] might support the future development of GEMMA and PDMA as analytical as well as micropreparative tools.

\section{Acknowledgments}

The authors acknowledge support of the PDMA research by the Austrian Science Foundation grant P16185 (to W.W.S.) and the patent offices of the Vienna University of Technology as well as University of Vienna. The authors thank F. L. Dickert for the generous gift of TMV, D. Blaas for the VLDL and P. Messner for the TEM pictures.

\section{References}

1. Lisby, M.; Rothstein, R. DNA Damage Checkpoint and Repair Centers. Curr. Opin. Cell Biol. 2004, 16, 328-334.

2. Allemann, R. K.; Egli, M. DNA Recognition and Bending. Chem. Biol. 1997, 4, 643-650.

3. Tormo, J.; Centeno, N. B.; Fontana, E.; Bubendorfer, T.; Fita, I.; Blaas, D. Docking of a Human Rhinovirus Neutralizing Antibody onto the Viral Capsid. Proteins 1995, 23. 
4. Horn, F.; Moc, I.; Schneider, N.; Grillhösl, C.; Berghold, S.; Lindemeier, G. Biochemie des Menschen; Thieme: Stuttgard, 2005.

5. Schreiber, G. Kinetic studies of protein-protein interactions. Curr. Opin. Cell Biol. 2002, 12, 41-47.

6. Hinds, W. C. Aerosol Technology: Properties, Behavior, and Measurement of Airborne Particles; Wiley: New York, 1999.

7. Reischl, G. P.; Makela, J. M.; Necid, J. Performance of a Vienna-Type Nano-DMA at 1.2 to $20 \mathrm{~nm}$. Aerosol Sci. Technol. 1997, 27, 651-672.

8. (a) Pui, D. Y. H.; Chen. D. R. Nanometer Particles: A New Frontier for Multidisciplinary Research. J. Aerosol Sci. 1997, 28, 539-544. (b) Koropchak, J. A.; Sadain S.; Yang, X.; Magnusson, L.-E.; Heybroek, M.; Anisimov, M.; Kaufman, S. L. Nanoparticle Detection Technology for Chemical Analysis. Anal. Chem. 1999, 71, 386A-394A. (c) Kaddis, C. S.; Loo J. A. Native Protein MS and Ion Mobility: Large Flying Proteins with ESI. Anal. Chem. 2007, 79, 1778-1784.

9. Reischl, G. P.; Makela, J. M.; Karch, R.; Necid, J. Bipolar Charging of Ultrafine Particles in the Size Range Below $10 \mathrm{~nm}$. J. Aerosol. Sci. 1996, 27, 931-949.

10. Fuchs, N. A. On the Stationary Charge Distribution on Aerosol Particles in Bipolar Ionic Atmosphere. Geofis. Pura. Appl. 1963, 56, 185-193.

11. (a) Bacher, G.; Szymanski, W. W.; Kaufman, S. L.; Zöllner, P.; Blaas, D.; Allmaier, G. Charge Reduced Nano-Electrospray Combined with Differential Mobility Analysis of Peptides, Proteins, Glycoproteins, Noncovalent Protein Complexes, and Viruses. J. Mass Spectrom 2001, 36, 1038-1052. (b) Thomas, J. J.; Bothner, B.; Traina, J.; Benner, W. H.; Siuzdak, G. Electrospray Ion Mobility Spectrometry of Intact Viruses. Spectroscopy 2004, 18, 31-36.

12. (a) Loo, J. A.; Berhane, B.; Kaddis, C. S.; Wooding, K. M.; Xie, Y.; Kaufman, S. L.; Chernushevich, I. V. Electrospray Ionization Mass Spectrometry and Ion Mobility Analysis of the 20S Proteasome Complex J. Am. Soc. Mass Spectrom. 2005, 16, 998-1008. (b) Kaddis, C. S.; Lomeli, S. H.; Yin, S.; Berhane, B.; Apostol, M. I.; Kickhoefer, V. A.; Rome, L. H.; Loo, L. A. Sizing Large Proteins and Protein Complexes by Electrospray Ionization Mass Spectrometry and Ion Mobility. J. Am. Soc. Mass Spectrom. 2007, 18, 1206-1216.

13. Laschober, C.; Wruss, J.; Blaas, D.; Szymanski, W. W.; Allmaier, G. Gas Phase Electrophoretic Molecular Mobility Analysis of Size and Stoichiometry of Complexes of a Common Cold Virus with Antibody and Soluble Receptor Molecules. Anal. Chem. 2008, 80, 2261-2264.

14. (a) Wick, C. H.; McCubbin, P. E. Characterization of Purified MS2 Bacteriophage by the Physical Counting Methodology Used in the Integrated Virus Detection System (IVDS). Toxicol. Methods 1999, 9 245-252. (b) Hogan C. J.; Kettleson, E. M.; Ramaswami, B.; Chen, D. R.; Biswas, P. Charge Reduced Electrospray Size Spectrometry of Megaand Gigadalton Complexes: Whole Viruses and Virus Fragments. Anal. Chem. 2006, 78, 844-852.

15. Müller, R.; Laschober, C.; Szymanski, W. W.; Allmaier, G. Determination of Molecular Weight, Particle Size, and Density of High Number Generation PAMAM Dendrimers using MALDI-TOF-MS and nESGEMMA. Macromolecules 2007, 40, 5599-5605.

16. Saucy, D.; Ude, S.; Lenggoro, W.; de la Mora, J. F. Mass Analysis of Water-Soluble Polymers by Mobility Measurement of Charge-Reduced Electrosprays. Anal. Chem. 2004, 76, 1045-1053.

17. Takashima, K.; Suga, T.; Mamiya, G. The Structure of Jack Bean Urease. The Complete Amino Acid Sequence, Limited Proteolysis and Reactive Cysteine Residues. Eur. J. Biochem. 1988, 175, 161-165.

18. Omar, S.; Beauregard, M. Dissociation and Unfolding of Jack Bean Urease Studied by Fluorescence Emission Spectroscopy. J. Biotechnol. 1995, 39, 221-228.
19. Krauss, R. M. Relationship of Intermediate and Low Density Lipoprotein Subspecies to Risk of Coronary Heart Disease. Am. Heart. J. 1987, $113,578-582$

20. Austin, M. A.; Breslow, J. L.; Hennekens, C. H.; Buring, J. E.; Wilett, W. C.; Krauss, R. M. Low Density Lipoprotein Subclass Patterns and Risk of Myocardial Infarction. J. Am. Med. Assoc. 1988, 260, 1917-1921.

21. Campos, H.; Genest, J. J.; Blijlevens, E. Low Density Lipoprotein Particle Size and Coronary Artery Disease. Arthereoscler. Thromb. 1992, 12 187-195.

22. McNamara, J. R.; Warnick, R. G.; Cooper, G. R. A Brief History of Lipid and Lipoprotein Measurements and Their Contribution to Clinical Chemistry. Clin. Chim. Acta 2006, 369, 158-167.

23. Blake, G. J.; Otvos, J. D.; Rifai, N.; Ridker, P. M. Low-Density Lipoprotein Particle Concentration and Size as Determined by Nuclear Magnetic Resonance Spectroscopy as Predictors of Cardiovascular Disease in Women. Circulation 2002, 106, 1930-1937.

24. Benner, H. W.; Krauss, R. M.; Blanche, P. J. United States patent 7259018; issued 21 August 2007.

25. (a) Schmid, M. F.; Prasad, B. V.; W. C. Structural Studies of Viruses by Electron Cryomicroscopy. Arch. Virol. Suppl. 1994, 9, 523-529. (b) Harrison, B. D.; Wilson, T. M. A. Milestones in the Research on Tobacco Mosaic Virus. Phil. Trans. R. Soc. Lond. B 1999, 354, 521-529.

26. Cloupeau, M.; Prunet-Foch, B. Electrostatic Spraying of Liquids in Cone-Jet Mode. J. Electrostat. 1989, 22, 135-159.

27. Allmaier, G., Laschober, C., Reischl, G. P., Szymanski, W. W. Austrian patent 502207 A1 200702 15. Patent issued 15 February, 2007

28. Seol, K. S.; Tsutatani, Y.; Camata, R. P.; Yabumoto, J.; Isomura, S. Okada, Y.; Okuyama, K.; Takeuchi, K. A Differential Mobility Analyzer and a Faraday Cup Electrometer for Operation at 200 to 930 Pa Pressure. J. Aerosol. Sci. 2000, 31, 1389-1395.

29. Maisser, A.; Laschober, C.; Allmaier, G.; Szymanski, W. W. Measurement of Size Distributions and Viability of Nanobioaerosols. Proceedings of the European Aerosol Conference Abstract T04A007; Salzburg, Austria, September, 2007.

30. Hussain, M. M. A Proposed Model for the Assembly of Chylomicrons Atherosclerosis 2000, 148, 1-15.

31. Lemieux, I.; Coulliard, C.; Pascot, A.; Bergeron, N.; Denis, P. h.; Bergeron, J.; Tremblay, A.; Bouchard, C.; Mauriege, P.; Despres, J.-P. The Small, Dense LDL Phenotype as a Correlate of Postprandial Lipidemia in Men. Atherosclerosis 2000, 153, 423-432.

32. Pascot, A.; Lemieux, I.; Prud'homme, D.; Tremblay, A.; Nadeau, A. Coulliard, C.; Bergeron, J.; Lamarche, B.; Despres, J.-P. Reduced HDL Particle Size as an Additional Feature of the Anthropogenic Dyslipidemia of Abdominal Obesity. J. Lipid. Res. 2001, 42, 2007-2014.

33. Friedewald, W. T.; Levy, R. I.; Fredrickson, D. S. Estimation of the Concentration of Low-Density Lipoprotein Cholesterol in Plasma Without Use of the Preparative Ultracentrifuge. Clin. Chem. 1972, 18, $499-$ 502.

34. Harrison, B. D.; Wilson, T. M. A. Milestones in the Research on Tobacco Mosaic Virus. Phil. Trans. R. Soc. Lond. B 1999, 354, 521-529.

35. Siuzdak, G.; Bothner, B.; Yeager, M.; Brugidou, C.; Fauquet C. M.; Hoey K.; Chang, C. M. Mass Spectrometry and Viral Analysis. Chem. Biol. 1996, 3, 45-48.

36. Laschober, C.; Kaufman, S.; Reischl, G.; Allmaier, G.; Szymanski, W. Comparison Between an Unipolar Corona Charger and a PoloniumBased Bipolar Neutralizer for the Analysis of Nanosized Particles and Biopolymers. J. Nanosci. Nanotech. 2006, 6, 1474-1481.

37. De la Mora, J. F.; De Juan, L.; Eichler, T.; Rosell, J. Differential Mobility Analysis of Molecular Ions and Nanometer Particles. TRAC 1998, 17, 328-339. 